\title{
First Ply Failure Behaviour of Laminated Composite Skew Plate under Concentrated Load
}

\author{
Ravi Kumar, Dona Chatterjee, Arghya Ghosh and Dipankar Chakravorty
}

\begin{abstract}
The present work envisages the first ply failure analysis of laminated composite skew plate using ANSYS 19.1 R. The finite element model is developed using 4-noded 3D shell-181 element with six degrees of freedom per node (three translations and three rotations). Numerical experiments are conducted considering skew plate of varying skew angles, laminations, stacking patterns and boundary conditions with central concentrated load. First ply failure loads are evaluated considering three different failure criteria such as maximum stress, maximum strain and those proposed by Tsai-Wu. The minimum value of load obtained from three criteria is chosen as governing first ply failure load value. Benchmark problems are solved to validate the correctness of the present approach of evaluation of first ply failure load incorporation of skew geometry in the present numerical model. The results are finally post processed to arrive some meaningful engineering conclusions.
\end{abstract}

Keywords - First ply failure, laminated composite, skew plate, finite element analysis, ANSYS

\section{INTRODUCTION}

Composite skew plates are having various applications in high performance modern engineering structures, ships, highway bridges, skew grid of beams and girders, thin plate structures etc. The analysis of skew plate gained attention by researchers in the late 1940s. In general, analysis of skew plate is more complex than rectangular ones. The exact solution for structural response of skew plate is limited to some specific cases therefore solution of partial differential equation can be obtained using analytical or numerical method. Numerical methods such as finite element method, finite differential quadrature method etc. are employed for the analysis of skew plate.

The first ply failure load of laminated composite skew plate under uniformly distributed load using ANSYS were

Manuscript revised June 30, 2020 and published on July 10, 2020

Ravi Kumar, ME Student, Department of Civil Engineering, Jadavpur University, Kolkata, India.

Dona Chatterjee, PhD Student, Department of Civil Engineering, Jadavpur University, Kolkata, India.

Dr. Arghya Ghosh, Visiting Faculty, Department of Civil Engineering, Jadavpur University, Kolkata, India

Dr. Dipankar Chakravorty, Professor, Department of Civil Engineering, Jadavpur University, Kolkata, India studied by Saha et al. [1] studied the outcome of various factors such as perpendicular distance, angle of twist, mid surface delamination and non-dimensional velocity on first ply failure strength of conical shaped shallow shell. Authors obtained numerical results using finite element method with the implementation of various failure criteria such as maximum stress, Tsai-Hill, Tsai-Wu and Hoffman. First ply failure of a laminated composite skewed thin hypar shell roof using nonlinear finite element approach was studied and reported by Ghosh and Chakravorty [2]. The results suggest that Pucks criteria can be universally adopted to get the first ply failure load. Also angle ply shell performs better than cross ply shell in terms of first ply failure.

Kumar et al. [3] reported the uniformly distributed first ply failure load laminated composite skew plate with a finite element model developed based on higher order shear deformation theory [HSDT]. Authors presented the first ply failure load of the cross ply and angle ply composite skew plate under uniformly distributed load for different boundary conditions. The results states that as the skew angle increases, failure load value increases for both CCCC and SSSS boundary conditions and also for a given skew angle failure load increases as the boundary condition changes from simply supported to clamped.

Joshi [4] presented the failure analysis of laminated composite plate, of graphite/epoxy, using higher order shear deformation theory. Various failure theories such as maximum stress, maximum strain, Tsai-Wu etc. are used with both symmetric and antisymmetric lamination scheme under simply supported condition. The results suggest that failure load increases with increase in fiber orientation angle.

Multi scale modelling and failure analysis of composites using finite element software ANSYS was presented by Uniyal et al. [5]. Authors used various failure theories such as maximum stress, maximum strains, Tsai-Wu and first ply failure load values were obtained for different lamination schemes under uniaxial and biaxial loading conditions.

Bakshi et al. [6] investigated the first ply failure load of moderately thin composite conoidal shell under normal uniformly distributed load using various failure theories. The results suggest that cross ply and angle ply laminates always tend to fail in in-plane shear of the bottommost fiber and transverse tensile strain respectively. Authors also concluded that cross ply stacking sequence exhibits better performance than angle ply stacking in terms of first ply failure load for conoidal shell. Adali and Cagdas [7] studied and reported the effect of fiber orientation on failure strength of a laminated 
curved panel under the action of uniaxial compression. They defined failure load as minimum of first ply failure and buckling load. The results suggest that for a thick cylindrical panel failure was mostly due to first ply failure while for thin cylindrical panels, buckling mode of failure dominates. Pal and Bhattacharya [8] carried out the linear progressive failure analysis of laminated composite plate under transverse loading based on FSDT. The results suggest that ultimate failure load increases with the increase in angle of fiber orientation for both symmetric and antisymmetric cross ply laminated plate consisting of different number of layers. Akhras and Li [9] observed and reported that load at which total laminate fails and marked that ulimate failure load was far above than the load at which failure initiates. However, for the design dependability an engineer should be well known about first ply failure because if commencement of damage remains undiscovered then it may lead to severe damage and sudden collapse of structure. The progressive failure analysis of laminated stiffened and unstiffened composite plate, subjected to transverse static loading, using finite element method was studied by Prusty [10]. The results suggest that in almost all cases failure of laminated composite plate or shell happened before the stiffener laminate and location of failure was at the centre of the plate or shell. It was found that Tsai- Wu theory was considered for progressive failure analysis and for first ply failure analysis most prominent failure theories such as maximum stress, maximum strain, Hoffman etc. were used.

Naresh and Muthu [11] studied the load deflection behavior of simply supported skew plate under the action of uniformly distributed transverse load. Suman et al. [12] presented the bending of skew plate and obtained the governing differential equation using first order shear deformation theory (FSDT) and Hamilton theory. Ikharrane et al. [13] developed a numerical tool that could be useful in obtaining approximate solution of bending problem of composite skew plate subjected to various loadings under different support conditions. Manjunath et al. [14] presented the linear static failure analysis of rhombus type skew plate under uniformly distributed load.

It is clear from the review the areas of first ply failure and skew plate analysis have received attention individually but failure study of composite skew plate was reported only by Kumar and Chakrabarty [3]. The present research studies and reports the first ply failure analysis of laminated composite skew plate roof under concentrated load with varying parameters and boundary conditions using ANSYS mechanical APDL.

\section{MAThematical Formulation}

Consider a laminated composite skew plate having skew angle of $\alpha$ as shown in Figure 1 having uniform thickness of $h$ and all four sides are equal in length. It consists of a number of thin lamina bonded together to form laminate, fibers of which are oriented at certain angle $\theta$ with global $x$-axis of the plate. The axes system is taken at mid surface (i.e. reference plane) of the laminated plate system. The present study considers a four-noded isoparametric shell element with three translations $(u, v, w)$ along $X, Y$ and $\mathrm{Z}$ directions and three rotations $\left(\alpha_{x}, \alpha_{y}, \alpha_{z}\right)$ about $X, Y$ and $Z$ directions respectively at each node .

\section{Displacement field}

First order shear deformation theory is used in the present study. The displacement field of a laminated composite plate can be expressed using first order shear deformation theory as,

$$
\begin{aligned}
& u(X, Y, Z)=u_{0}(X, Y)+Z \alpha_{x}(X, Y) \\
& v(X, Y, Z)=v_{0}(X, Y)+Z a_{y}(X, Y) \\
& w(X, Y, Z)=w_{0}(X, Y)+Z \alpha_{z}(X, Y)
\end{aligned}
$$

here $u, v$ and $w$ on left side of the equation represent the 3D deformation of any point expressed in 2D in terms of midplane displacement $u_{0}, v_{0}$ and $w_{0}$. The rotations of normal to the mid surface about $Y, X$ and $Z$ axes are $\theta_{X}, \theta_{Y}$ and $\theta_{Z}$ respectively. Strains can be obtained by derivation of displacements as:
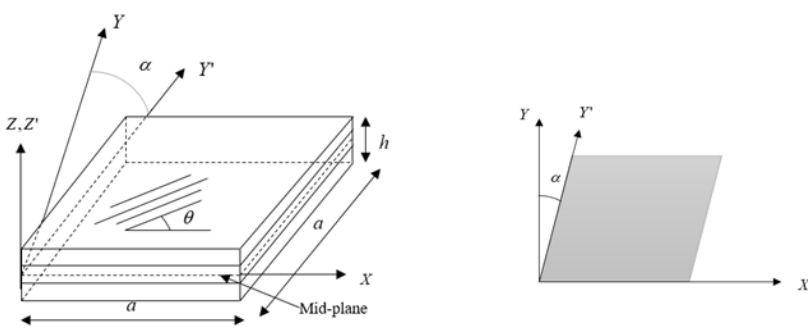

Fig. 1. Schematic diagram of laminated composite skew plate

$$
\left\{\begin{array}{l}
\varepsilon_{X} \\
\varepsilon_{Y} \\
\varepsilon_{Z} \\
\gamma_{X Y} \\
\gamma_{Y Z} \\
\gamma_{Z X}
\end{array}\right\}=\left\{\begin{array}{l}
\partial u / \partial X \\
\partial v / \partial Y \\
\partial w / \partial Z \\
\partial u / \partial Y+\partial v / \partial X \\
\partial v / \partial Z+\partial w / \partial Y \\
\partial w / \partial Z+\partial w / \partial X
\end{array}\right\}
$$

Here $X, Y, Z$ are three global co-ordinate axes of skew plate model in ANSYS. The in plane strain and transverse strain vectors are:

$$
\left\{\begin{array}{l}
\varepsilon_{X} \\
\varepsilon_{Y} \\
\gamma_{X Y}
\end{array}\right\}=\left\{\begin{array}{l}
\varepsilon_{X}^{0} \\
\varepsilon_{Y}^{0} \\
\gamma_{X Y}^{0}
\end{array}\right\}+Z\left\{\begin{array}{l}
k_{X} \\
k_{Y} \\
k_{X Y}
\end{array}\right\} ; \quad\left\{\begin{array}{l}
\varepsilon_{Z} \\
\gamma_{Y Z} \\
\gamma_{X Z}
\end{array}\right\}=\left\{\begin{array}{l}
\varepsilon_{Z}^{0} \\
\gamma_{Y Z}^{0} \\
\gamma_{X Z}^{0}
\end{array}\right\}+Z\left\{\begin{array}{l}
k_{Z} \\
k_{Y Z} \\
k_{X Z}
\end{array}\right\}
$$

where the deformation components are described as:

$$
\left\{\begin{array}{l}
\varepsilon_{X}^{0} \\
\varepsilon_{Y}^{0} \\
\gamma_{X Y}^{0}
\end{array}\right\}=\left\{\begin{array}{l}
\partial u_{o} / \partial X \\
\partial v_{o} / \partial Y \\
\partial u_{o} / \partial Y+\partial v_{o} / \partial X
\end{array}\right\} ; \quad\left\{\begin{array}{l}
k_{X} \\
k_{Y} \\
k_{X Y}
\end{array}\right\}=\left\{\begin{array}{l}
\partial \alpha_{X} / \partial X \\
\partial \alpha_{Y} / \partial Y \\
\partial \alpha_{X} / \partial Y+\partial \alpha_{Y} / \partial X
\end{array}\right\}
$$


$\left\{\begin{array}{l}\varepsilon_{Z}^{0} \\ \gamma_{Y Z}^{0} \\ \gamma_{X Z}^{0}\end{array}\right\}=\left\{\begin{array}{l}\alpha_{Z} \\ \partial w_{o} / \partial Y+\alpha_{Y} \\ \partial w_{o} / \partial X+\alpha_{X}\end{array}\right\} \quad\left\{\begin{array}{l}k_{Z} \\ k_{Y Z} \\ k_{X Z}\end{array}\right\}=\left\{\begin{array}{l}0 \\ \partial \alpha_{Z} / \partial Y \\ \partial \alpha Z / \partial X\end{array}\right\}$

\section{Strain displacement relation}

$\{\varepsilon\}=[B]\{\Delta\}$

where $[B]$ is the strain displacement matrix and $\{\Delta\}=\left\{u_{0}, v_{0}, w_{0}, \alpha_{x}, \alpha_{y}, \alpha_{z}\right\}^{T}$ is the nodal displacement vector.

\section{Constitutive relationship}

$$
\{\sigma\}=[E]\{\varepsilon\}
$$

where $\{\sigma\}$ and $\{\varepsilon\}$ are the in plane stress-strain vector respectively and $[E]$ is the laminate stiffness matrix. Here strain displacement matrix $[B]$ and laminate stiffness matrix $[E]$ are adopted from those used by Ghosh and Chakravorty [2].

\section{Finite element formulation}

The finite element method used here for numerical solution of complex skew plate problem subjected to transverse concentrated load. A 4-noded quadrilateral element is used to develop the present formulation. It is a element (refer Figure 2) with six degrees of freedom at each node. The displacement of any point on surface of any element $\{u\}$ can be written in terms of joint displacement $\left\{d_{e}\right\}$ with the help of interpolation functions $[N]$ as,

$$
\begin{aligned}
& \{u\}=[N]\left\{d_{e}\right\} \\
& u=\sum_{i=1}^{4} N_{i} u_{i} ; v=\sum_{i=1}^{4} N_{i} v_{i} ; w=\sum_{i=1}^{4} N_{i} w_{i} ; \\
& \alpha_{x}=\sum_{i=1}^{4} N_{i} \alpha_{x i} ; \alpha_{y}=\sum_{i=1}^{4} N_{i} \alpha_{y i} ; \alpha_{z}=\sum_{i=1}^{4} N_{i} \alpha_{z i}
\end{aligned}
$$

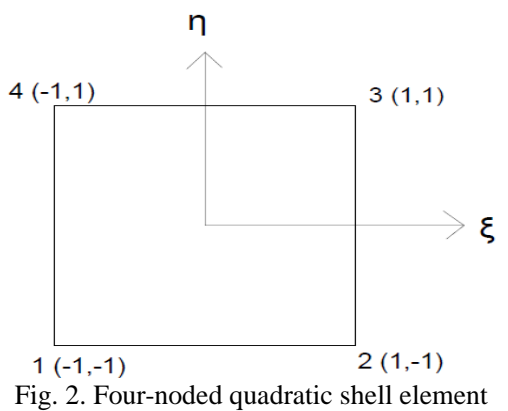

The interpolation functions are given as,

$$
\begin{aligned}
& N_{1}=1 / 4(1+\xi)(1-\eta) ; N_{2}=1 / 4(1+\xi)(1-\xi) \\
& N_{3}=1 / 4(1+\xi)(1+\eta) ; N_{4}=1 / 4(1-\xi)(1+\eta)
\end{aligned}
$$

\section{Governing equations}

The governing equilibrium equation of linear elastic problem for a body undergoing infinitely small displacement can be derived from the principle of minimum total potential energy ' $U_{1}$ ' consisting of external work ' $W$ ' and strain energy ' $U$ '

$U_{1}=U+W$

Strain energy, $U$ is given as

$U=\frac{1}{2} \iint\{\Delta\}^{\mathrm{T}}[\mathrm{B}]^{\mathrm{T}}[\mathrm{E}][\mathrm{B}]\{\Delta\} \mathrm{dx} d \mathrm{y}$

And the work done is expressed as,

$W=-\iint\{\Delta\}^{T}[N]^{T}[q] \mathrm{dx} \mathrm{dy}$

The element stiffness matrix can be obtained using the principle of minimum potential energy.

Potential energy of plate is given as:

$U_{1}=\frac{1}{2} \iint\{\Delta\}^{\mathrm{T}}[\mathrm{B}]^{\mathrm{T}}[\mathrm{E}][\mathrm{B}]\{\Delta\} \mathrm{dx} \mathrm{dy}-\iint\{\Delta\}^{T}[N]^{T}[q] \mathrm{dx} \mathrm{dy}$

From the principle of minimum total potential energy of the plate with respect to its deformations, following condition needs to satisfy,

$\left\{\frac{\partial U_{1}}{\partial \Delta}\right\}=\iint[\mathrm{B}]^{\mathrm{T}}[\mathrm{E}][\mathrm{B}]\{\Delta\} \mathrm{dx} \mathrm{dy}-\iint[N]^{T}[q] \mathrm{dx} \mathrm{dy}=\{0\}$

Equation (14) can also be written in form of as,

$[K]\{\Delta\}=\{F\}$

where, $[K]=\iint[\mathrm{B}]^{\mathrm{T}}[\mathrm{E}][\mathrm{B}]\{\Delta\} \mathrm{dx}$ dy and $\{F\}=\iint[N]^{T}[q] \mathrm{dx} \mathrm{dy}$ The element stiffness matrix $[K]$ and mass matrix $[M]$ can be expressed as

$\left.[K]=\int_{-1}^{+1} \int_{-1}^{+1}[B]^{T}[E] B\right]|J| d \xi d \eta \quad ;[M]=\int_{-1}^{+1} \int_{-1}^{+1}[N]^{T}[m][N]|J| d \xi d \eta$

The determinnt of Jacobian matrix is given by $|J|$, mass matrix is indicated as $[m]$ and $[N]$ is the shape function matrix. The integration is carried out by "Gaussian quadrature rule".

where $\{F\}$ is the external load acting at the nodes. The above equation (15) can be solved by imposing boundary condition and solution algorithm.

\section{Boundary conditions}

Imposing boundary conditions means the presence or absence of the generalized displacements $u, v, w, \theta_{x}, \theta_{y}$ and $\theta_{z}$ in the different nodes of the discretized structure. Two boundary conditions (as shown in Figure 3(a) and (b)) have been considered in the present study are described as below: Case1: All edges are clamped (CCCC)

Where $u=v=w=\theta_{x}=\theta_{y}=\theta_{z}=0$ 
Case2: All edges are simply supported (SSSS)

Where $u=v=w=1 ; \theta_{x}=\theta_{y}=\theta_{z}=0$
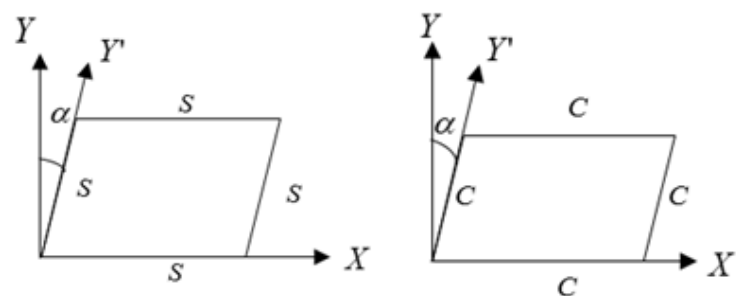

Fig. 3. (a) All edges are simply supported (b) All edges are clamped

\section{Numerical Problems}

A convergence study is carried out to optimize the number of finite elements required to represent the plate surface and the results are reported in Table 1 . The convergence is considered as achieved when the first ply failure loads are within $10 \%$ to $15 \%$ of that found in the selected literature. A $12 \times 12$ mesh is found to be the optimum one in the present case to solve first ply failure problems of laminated composite plate as evident from Table 1.

\begin{tabular}{llccc}
\multicolumn{4}{l}{ TABLE 1: MESH CONVERGENCE STUDY FOR FIRST PLY FAILURE LOAD (N) } \\
\hline \hline Lamination & $\begin{array}{c}\text { Maximum } \\
\text { stress }\end{array}$ & $\begin{array}{c}\text { Maximum } \\
\text { strain }\end{array}$ & Tsai-Wu \\
\hline Kam et al. [15] & 64.94 & 76.04 & 68.30 \\
Present & $(4 \times 4)$ & 221.14 & 273.97 & 247.95 \\
FEM & $(12 \times 12)$ & 61.76 & 70.32 & 57.74 \\
\hline \hline
\end{tabular}

Two different published problems have been taken from above literatures for validating the present approach. The first ply failure loads of composite plates as reported by Kam et al. [15] are used to compare the present results with the published ones- as furnished in Table 2. To establish the correct modeling of skew plate geometry the natural frequencies of such plates are calculated by the present approach and compared with those reported by Singha and Daripa [16] in Table 3.

TABLE 2: CONCENTRATED FIRST PLY FAILURE LOADS IN NEWTON FOR $\left[0^{\circ} / 90^{\circ}\right] \mathrm{S}$ PLATE

\begin{tabular}{lllll}
\multicolumn{5}{c}{$\left[0^{\circ} / 90^{\circ}\right]$ S PLATE } \\
$\begin{array}{l}\text { Governing } \\
\text { criteria of } \\
\text { failure }\end{array}$ & $\begin{array}{l}\text { Thickness } \\
\text { ratio }\end{array}$ & $\begin{array}{l}\text { Experiment } \\
\text { al failure } \\
\text { loads } \\
{[\text { Kam et al. }}\end{array}$ & $\begin{array}{l}\text { First ply } \\
\text { failure loads } \\
{[\text { Kam et al. }} \\
[15]]\end{array}$ & $\begin{array}{l}\text { First ply } \\
\text { failure } \\
\text { loads } \\
\text { (ANSYS) }\end{array}$ \\
\hline $\begin{array}{l}\text { Maximum } \\
\text { stress }\end{array}$ & 158.08 & 64.94 & 61.766 \\
$\begin{array}{l}\text { Maximum } \\
\text { strain }\end{array}$ & 152.67 & 76.04 & 70.323 \\
$\begin{array}{l}\text { Tsai-Wu } \\
\text { Note: Dimension of plate }=100 \text { mm, thickness of each ply }=0.155 \mathrm{~mm}, \text { load } \\
\text { type }=\text { central applied concentrated load }\end{array}$ & & 57.736 \\
\hline \hline
\end{tabular}

type $=$ central applied concentrated load

\begin{tabular}{|c|c|c|c|c|c|}
\hline \multicolumn{2}{|c|}{$\operatorname{FREQUENCY}(\bar{\omega})=\left(\omega a^{2} / \pi^{2}\right)$} & \multicolumn{4}{|c|}{$\frac{\rho}{E_{T}}$ OF FIVE LAYERED $\left[90^{\circ} / 0^{\circ} / 90^{\circ} / 0^{\circ} / 90^{\circ}\right]$} \\
\hline \multicolumn{6}{|c|}{ SIMPLY SUPPORTED SKEW PLATE (ASPECT RATIO=1) } \\
\hline \multirow{2}{*}{\multicolumn{2}{|c|}{$\begin{array}{l}\text { Skew Angle } \\
\text { Thin plate }(\mathrm{a} / \mathrm{h}=1000)\end{array}$}} & \multirow{2}{*}{$\begin{array}{l}\text { Mesh } \\
\text { sizes }\end{array}$} & \multicolumn{3}{|c|}{ Modes } \\
\hline & & & 1 & 2 & 3 \\
\hline \multirow[t]{2}{*}{$0^{\circ}$} & $\begin{array}{l}\begin{array}{l}\text { Present } \\
\text { (ANSYS) }\end{array} \\
\text { study }\end{array}$ & $8 \times 8$ & 1.913 & 3.986 & 6.664 \\
\hline & Singha et al. [16] & & 1.914 & 3.973 & 6.645 \\
\hline \multirow[t]{2}{*}{$30^{\circ}$} & $\begin{array}{l}\text { Present study } \\
\text { (ANSYS) }\end{array}$ & & 2.918 & 5.333 & 8.893 \\
\hline & Singha et al. [16] & $8 \times 8$ & 2.838 & 5.195 & 8.464 \\
\hline
\end{tabular}

Additional problems on laminated composite skew plates under central concentrated load with various edge conditions and laminations are solved for different skew angles. The different boundary conditions which are solved includes fully clamped (CCCC) and fully simply supported (SSSS). The laminations considered for the present study are antisymmetric angle ply (ASAP), antisymmetric cross ply (ASCP), symmetric angle ply (SYAP) and symmetric cross ply (SYCP). The material properties of graphite-epoxy and the geometrical parameters used by the authors for the present study are presented in Table 4 and Table 5 respectively.

TABLE 4: MATERIAL PROPERTIES OF Q-1115 GRAPHITE EPOXY COMPOSITE MATERIAL

\begin{tabular}{llllll}
\hline \hline $\begin{array}{l}\text { Mechanical } \\
\text { properties }\end{array}$ & Values & $\begin{array}{l}\text { Strength } \\
\text { parameters }\end{array}$ & $\begin{array}{l}\text { Values } \\
(\mathrm{MPa})\end{array}$ & $\begin{array}{l}\text { Strain } \\
\text { strength } \\
\text { parameters }\end{array}$ & Values \\
\hline $\mathrm{E}_{11}$ & 142500 & $\sigma_{\mathrm{xt}}$ & 2193.5 & $\varepsilon_{\mathrm{xt}}$ & 0.01539 \\
$\mathrm{E}_{22}$ & 9790 & $\sigma_{\mathrm{vt}}$ & 41.3 & $\varepsilon_{\mathrm{vt}}$ & 0.00412 \\
$\mathrm{E}_{33}$ & 9790 & $\sigma_{\mathrm{zt}}$ & 41.3 & $\varepsilon_{\mathrm{zt}}$ & 0.00412 \\
$\mathrm{G}_{12}$ & 4720 & $\sigma_{\mathrm{xc}}$ & 2457.0 & $\varepsilon_{\mathrm{xc}}$ & 0.01724 \\
$\mathrm{G}_{13}$ & 4720 & $\sigma_{\mathrm{yc}}$ & 206.8 & $\varepsilon_{\mathrm{yc}}$ & 0.02112 \\
$\mathrm{G}_{23}$ & 1192 & $\sigma_{\mathrm{zc}}$ & 206.8 & $\varepsilon_{\mathrm{zc}}$ & 0.02112 \\
$v_{12}$ & 0.27 & $\tau_{\mathrm{xv}}$ & 61.28 & $\gamma_{\mathrm{xv}}$ & 0.05141 \\
$v_{13}$ & 0.27 & $\tau_{\mathrm{xz}}$ & 78.78 & $\gamma_{\mathrm{xz}}$ & 0.01669 \\
$v_{23}$ & 0.25 & $\tau_{\mathrm{yz}}$ & 78.78 & $\gamma_{\mathrm{yz}}$ & 0.01669 \\
\hline \hline
\end{tabular}

TABLE 5: GEOMETRICAL PROPERTIES OF THE SKEW PLATE

\begin{tabular}{ll}
\hline \hline Parameters & Values \\
\hline Aspect ratio, $(\mathrm{a} / \mathrm{b})$ & 1 \\
Thickness, $\mathrm{t}(\mathrm{mm})$ & 10 \\
Skew angles, $\alpha$ (degree) & $0,15,30,45,60$ \\
\hline \hline
\end{tabular}

\section{RESUlTS AND DiscuSSIONS}

The results of the benchmark problems obtained by present method show good agreement with those obtained by Kam et al. (1996) establishing the correctness of the present approach in determination of first ply failure load (Refer Table 2). The correctness of the skew geometry formulation is established from comparison of results presented in Table 3. The other problems, which are solved to explore the different aspects of first ply failure behaviour of laminated composite skew plate, are also checked for convergence and only converged results are reported. Table 6 and 7 and Figure 4 and 5 furnishes the 
first ply failure loads with simply supported (SSSS) and clamped (CCCC) boundary conditions for different laminations and skew plate options.

\section{Concentrated first ply failure load of different skew plate options for various boundary conditions and laminations}

Once the correctness of the proposed software simulation is established, it is further used to compute first ply failure loads of laminated composite skew plate of several combination. A different combination of ASAP, ASCP, SYAP and SYCP plate with different skew angles ranging from $0^{\circ}$ to $60^{\circ}$ are investigated. The plates are considered to be loaded by central concentrated load. The first ply failure loads of the skew plate options are furnished in Tables 6 and Table 7 for symmetric and antisymmetric cross and angle-ply laminations respectively.

TABLE 6: CONCENTRATED FIRST PLY FAILURE LOADS OF FULLY CLAMPED (CCCC) SKEW PLATE OF VARIOUS SKEW ANGLES AND LAMINATIONS

\begin{tabular}{|c|c|c|c|}
\hline Laminations & Skew angle & Failure criteria & $\begin{array}{c}\text { First ply } \\
\text { failure load } \\
\text { applied as } \\
\text { central point } \\
\text { load (N) }\end{array}$ \\
\hline \multirow{5}{*}{$\begin{array}{c}\text { ASCP } \\
\left(0^{\circ} / 90^{\circ}\right)\end{array}$} & $0^{\circ}$ & Maximum stress & 8098.477 \\
\hline & $5^{\circ}$ & Tsai-Wu & 7412.898 \\
\hline & $30^{\circ}$ & Maximum stress & 8054.124 \\
\hline & $45^{\circ}$ & Maximum stress & 8907.098 \\
\hline & $60^{\circ}$ & Maximum stress & 11671.335 \\
\hline \multirow{5}{*}{$\begin{array}{c}\text { ASAP } \\
\left(+45^{\circ} /-45^{\circ}\right)\end{array}$} & $0^{\circ}$ & Maximum stress & 7137.758 \\
\hline & $15^{\circ}$ & Maximum stress & 7251.631 \\
\hline & $30^{\circ}$ & Maximum stress & 7645.260 \\
\hline & $45^{\circ}$ & Maximum stress & 8402.655 \\
\hline & $60^{\circ}$ & Maximum stress & 9943.323 \\
\hline \multirow{5}{*}{$\begin{array}{c}\text { SYCP } \\
\left(0^{\circ} / 90^{\circ} / 0^{\circ}\right)\end{array}$} & $0^{\circ}$ & Maximum stress & 12341.108 \\
\hline & $15^{\circ}$ & Maximum stress & 11960.292 \\
\hline & $30^{\circ}$ & Maximum stress & 11209.505 \\
\hline & $45^{\circ}$ & Maximum stress & 10400.416 \\
\hline & $60^{\circ}$ & Maximum stress & 9625.565 \\
\hline \multirow{5}{*}{$\begin{array}{c}\text { SYAP } \\
\left(+45^{\circ} /-45^{\circ} /+45^{\circ}\right)\end{array}$} & $0^{\circ}$ & Maximum stress & 8724.480 \\
\hline & $15^{\circ}$ & Maximum stress & 8433.125 \\
\hline & $30^{\circ}$ & Maximum stress & 8851.124 \\
\hline & $45^{\circ}$ & Maximum stress & 10316.723 \\
\hline & $60^{\circ}$ & Maximum stress & 11671.335 \\
\hline
\end{tabular}

TABLE 7: CONCENTRATED FIRST PLY FAILURE LOADS OF SIMPLY SUPPORTED (SSSS) SKEW PLATE OF VARIOUS SKEW ANGLES AND LAMINATIONS

\begin{tabular}{cccc}
\hline \hline Laminations & $\begin{array}{c}\text { Skew } \\
\text { angle }\end{array}$ & Failure criteria & $\begin{array}{c}\text { First ply } \\
\text { failure load } \\
\text { applied as } \\
\text { central point } \\
\text { load (N) }\end{array}$ \\
\hline ASCP & $0^{\circ}$ & Maximum stress & 7023.952 \\
$\left(0^{\circ} / 90^{\circ}\right)$ & $15^{\circ}$ & Maximum stress & 6809.670 \\
& $30^{\circ}$ & Maximum stress & 6917.064 \\
& $45^{\circ}$ & Maximum stress & 7523.888 \\
$\mathrm{ASAP}$ & $60^{\circ}$ & Maximum stress & 9338.812 \\
$\left(+45^{\circ} /-45^{\circ}\right)$ & $0^{\circ}$ & Maximum stress & 6561.249 \\
\hline
\end{tabular}

\begin{tabular}{|c|c|c|c|c|}
\hline & & $30^{\circ}$ & Maximum stress & 6769.105 \\
\hline & & $45^{\circ}$ & Maximum stress & 7338.372 \\
\hline & & $60^{\circ}$ & Maximum stress & 8029.549 \\
\hline & SYCP & $0^{\circ}$ & Maximum stress & 8886.519 \\
\hline & $\left.0^{\circ} / 90^{\circ} / 0^{\circ}\right)$ & $15^{\circ}$ & Maximum stress & 8675.284 \\
\hline & & $30^{\circ}$ & Maximum stress & 8277.460 \\
\hline & & $45^{\circ}$ & Maximum stress & 7908.264 \\
\hline & & $60^{\circ}$ & Maximum stress & 7641.170 \\
\hline & SYAP & $0^{\circ}$ & Maximum stress & 7462.686 \\
\hline$\left(+45^{\circ}\right.$ & $\left.\% /-45^{\circ} /+45^{\circ}\right)$ & $15^{\circ}$ & Maximum stress & 7147.963 \\
\hline & & $30^{\circ}$ & Maximum stress & 7160.759 \\
\hline & & $45^{\circ}$ & Maximum stress & 7861.017 \\
\hline & & $60^{\circ}$ & Maximum stress & 8751.969 \\
\hline \multirow{8}{*}{ 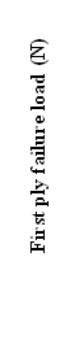 } & 14000 & & \multirow{2}{*}{\multicolumn{2}{|c|}{$\rightarrow-\operatorname{ASCP}\left(0^{*} / 90^{\circ}\right)$}} \\
\hline & 12000 & & & \\
\hline & 10000 & & \multicolumn{2}{|c|}{$\longrightarrow-\operatorname{ASAP}\left(+45^{\circ} / 45^{\circ}\right)$} \\
\hline & 6000 & & \multicolumn{2}{|c|}{$\triangle-\operatorname{SYCP}\left(+0 \%-90^{\circ} \%\right)$} \\
\hline & 4000 & & \multirow{2}{*}{\multicolumn{2}{|c|}{$-x-\operatorname{SYAP}\left(+45^{\circ} /-45^{\circ} \%+45^{\circ}\right)$}} \\
\hline & 2000 & & & \\
\hline & \multirow[t]{2}{*}{0} & 20 & \multirow{2}{*}{ le (degree) } & \\
\hline & & & & \\
\hline
\end{tabular}

Fig. 4. First ply failure load (Newton) versus skew angle for CCCC boundary condition

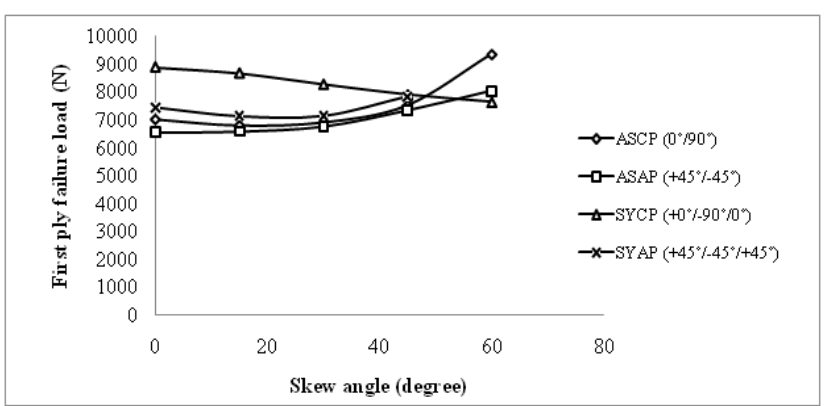

Fig. 5. First ply failure load (Newton) versus skew angle for SSSS boundary condition

Effect of skew angles on concentrated first ply failure load for various edge conditions

From the results of Table 6 and Table 7 and Fig. 4 to Fig. 5 it is evident that, as expected, the skew angle significantly affects the first ply failure load. It is interesting to note that as the skew angle increases from $0^{\circ}$ to $60^{\circ}$ the first ply failure load are found to be increasing for ASCP, ASAP and SYAP but a reverse trend is observed in case of SYCP lamination. So if design is done considering rectangular ASCP, ASAP and SYAP laminated plate it will be safe even if the plate becomes skew to any angle which does not holds good if the plate is of SYCP lamination.

\section{Effect of boundary condition on concentrated first ply failure load}

In general, for any given lamination and skew angle the clamped boundary condition turns out to be the stiffest one and yields the highest value of the first ply failure load (FPFL). This trend no doubt indicates the fact that to achieve high values of failure loads the boundaries should be clamped if possible. This conclusion is true for the class of plates that 
are considered here but no doubt there is a need of detailed investigation to identify the best edge condition when skew plates of other parametric variations are to be considered.

\section{Conclusion}

The following conclusions are drawn from the present study.

1. The present software simulation used here is suitable for first ply failure load analysis of laminated composite skew plate and yields excellent results of the benchmark problems.

2. As the skew angle increases from $0^{\circ}$ to $60^{\circ}$ for both the first ply failure load are found to be increasing for ASCP, ASAP and SYAP but a reverse trend is observed in case of SYCP lamination. So if design is done considering rectangular ASCP, ASAP and SYAP laminated plate it will be safe even if the plate becomes skew to any angle which does not holds good if the plate is of SYCP lamination.

3. Clamped (CCCC) plates shows highest first ply failure load (FPFL).

4. Authors observed that the cross ply plates are showing better response to angle ply ones. Likewise, among symmetric and antisymmetric laminates, the former are found to be far better than the later. Among all the skew angles, $60^{\circ}$ shows the best performance with $\mathrm{CCCC}$ as the best support condition.

\section{CONFLICT OF INTEREST}

"The authors declare no conflict of interest".

\section{REFERENCES}

[1] A Saha, A Das, A Karmakar, "Parametric Study on the First Ply Failure Load of Delaminated Shallow Pretwisted Conical Shells - A Finite Element Approach", Materials Today: Proceedings 11, pp. 818-829, 2019.

[2] A Ghosh, D Chakravorty, "First ply failure analysis of laminated composite thin hypar shells using nonlinear finite element approach", Thin-Walled Structures 131, pp. 736-745, 2018.

[3] A kumar, A Chakrabarty, "Failure analysis of laminated composite skew plate”, Procedia Engineering 173, pp. 1560 - 1566, 2017.

\section{AUTHORS PROFILE}

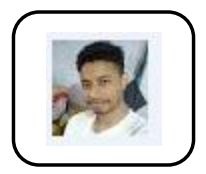

Ravi Kumar has completed his B.Tech from Heritage Institute of Technology, Kolkata. Presently he is pursuing his ME in Structural Engineering from Jadavpur University, Kolkata.
[4] R Joshi, "Failure analysis of laminated composite plate using HSDT", International Journal of Engineering Technology Science and Research, ISSN 2394 - 3386, pp. 252-260, Vol. 4, Issue No.10,2017.

[5] P Uniyal, D Gunwant and A Misra , "Multi Scale Modelling and Failure Analysis of Laminated Composites", Journal of Applied Mechanical Engineering, 5(6) ISSN: 2168-9873, 2016.

[6] K Bakshi, D Chakravorty, "First ply failure study of thin composite conoidal shells subjected to uniformly distributed load", Thin-Walled Structures, 76, pp. 1-7, 2014.

[7] S. Adali, I U. Cagdas, "Failure analysis of curved composite panels based on first-ply and buckling failures", Procedia Engineering, 10, 1591-1596, 2011.

[8] P Pal and S Bhattacharya, "Progressive failure analysis of cross-ply laminated composite plates by finite element method", Journal of reinforced plastics and composites, 26(5), 2007.

[9] G Akhras, WC Li, "Progressive failure analysis of thick composite plates using the spline finite strip method", Composite Structure, 79, 34-43, 2007.

[10] B. G Prusty, "Progressive failure analysis of laminated unstiffened and stiffened composite panels", Journal of Reinforced Plastic and Composites, 24(6), pp.633-642, 2005.

[11] G N Reddy, N.K.U Muthu, "Analysis of simply supported reinforced concrete skew slab", International Journal of Civil Engineering and Technology (IJCIET), 8(11), pp. 121-128, 2017.

[12] K S Suman, Vikas and J Singh, "Analysis of skew plate using FSDT", International Journal of Mechanical Engineering (IIJME), 4(3), pp. 5-11, 2016.

[13] L. Ikharrazne, "Design and analysis of composite skew plate bending", MATEC Web of Conferences 8347, 090032016.

[14] G. A Manjunath, R A Kumar, B Arvind, R Punith, "Finite element modeling for stress analysis of a rhombic skew plate structure", International Journal of Engineering Research \& Technology (IJERT), 3(2), pp. 2378-2287, 2014.

[15] T.Y. Kam, H.F. Sher, and T.N. Chao, "Prediction of deflection and first ply failure load of thin laminated composite plates via the finite element approach,” Int. J. Solids Structures. 33(3), pp. 375-398, 1996.

[16] M.K. Singha, and R. Daripa, "Nonlinear vibration of symmetrically laminated composite skew plates by finite element method," Int. J. of Nonlinear Mechanics. 42, pp. 1144-1152, 2007.

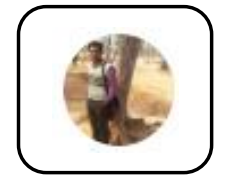

Dr. Arghya Ghosh completed his BE. ME and $\mathrm{PhD}$ in Civil Engineering with specialization in Structural Engineering from Jadavpur University, Kolkata. He has 8 years of academic and research experience. Presently he is working as visiting faculty at Jadavpur University.

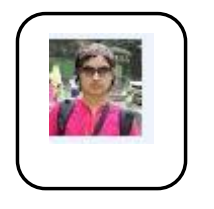

Dona Chatterjee is $\mathrm{BE}$ and ME in Civil Engineering with specialization in Structural Engineering from Jadavpur University, Kolkata. She has 3 years of design experience in industry and 6 years of teaching experience. Presently the author is pursuing her $\mathrm{PhD}$ degree from Jadavpur University, Kolkata.

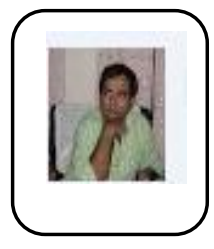

Dr. Dipankar Chakravorty works as Professor and Head at Department of Civil Engineering Jadavpur University, Kolkata. The author completed his BE Civil from Jadavpur University and M.Tech and $\mathrm{PhD}$ from IIT Kharagpur. The author has 26 years of academic and research experience. Author has guided a good number of $\mathrm{ME}$ and $\mathrm{PhD}$ students. 